\title{
SENTIMENTOS E EMOÇÕES: Uma Experiência no Contexto da Educação Infantil
}

\author{
Nathany Morais de Souza ${ }^{1}$ \\ Micarla Silva de Azevedo ${ }^{2}$ \\ Denise Cortez da Silva Accioly
}

\begin{abstract}
RESUMO
Este artigo é resultado de uma experiência de estágio na regência referente ao componente curricular Estágio II (Educação Infantil) do curso de Pedagogia pela UFRN/Ceres/Caicó. O texto tem como objetivo analisar a temática "sentimentos e emoções" no contexto da Educação Infantil e sua influência nas relações interpessoais e no processo de ensino-aprendizagem. Logo, a pesquisa foi realizada em uma instituição de Educação Infantil situada no município de Caicó/RN, e culminou na criação de um projeto na perspectiva dos sentimentos e emoções a fim de promover um ambiente empático e possibilitar a compreensão do eu, levando harmonia para dentro de sala de aula. Trata-se de uma pesquisa qualitativa que utilizou como recurso a pesquisa bibliográfica e a pesquisa de campo por meio da observação, além de ferramentas de cunho qualitativo. Por fim, o estudo se direciona para uma ação em sala de aula que, por sua vez, mostrou-se relevante ao longo dos dias, resultando em discussões e trabalhos que transparecem um bom desempenho processual na compreensão dos sujeitos acerca dos sentimentos e emoções.
\end{abstract}

Palavras-chave: sentimentos e emoções; educação infantil; relações interpessoais.

FEELINGS AND EMOTIONS: AN EXPERIENCE IN THE CHILDREN'S EDUCATION CONTEXT

\section{ABSTRACT}

This article is the result of an internship experience as a teacher, referring to the curricular component Stage II (Early Childhood Education) of the Pedagogy course by UFRN/Ceres/Caicó. It aims to analyze the theme "feelings and emotions" in the context of Early Childhood Education and its influence on interpersonal relationships and the teaching-learning process. Therefore, the research was carried out in an institution of Early Childhood Education, located in the city of Caicó/RN, where it culminated in the creation of a project from the perspective of feelings and emotions, in order to promote an empathic environment and enable the understanding of the self, taking harmony into the classroom. It is a qualitative research that used bibliographic research and field research through observation as a resource, in addition to qualitative tools. Finally, the study is directed to an action in the classroom that, in turn, has shown itself to be relevant over the days, resulting in discussions and work that show a good procedural performance in the understanding of the subjects about feelings and emotions.

Keywords: feelings and emotions; child education; interpersonal relationships.

Recebido em: $15 / 3 / 2020$

Aceito em: 26/4/2021

\footnotetext{
1 Autora correspondente. Universidade Federal do Rio Grande do Norte - UFRN, Centro de Ensino Superior do Seridó - Campus Caicó. Caicó/RN, Brasil. http://lattes.cnpq.br/0431314387185530.https://orcid.org/0000-0002-0213-3670.nathany.morais@hotmail.com

2 Universidade Federal do Rio Grande do Norte - UFRN. http://lattes.cnpq.br/5453872257503923. https://orcid.org/0000-0002-4013-9272.

3 Universidade Federal do Rio Grande do Norte - UFRN. http://lattes.cnpq.br/0492540368561302. https://orcid.org/0000-0001-8684-6573.
} 


\section{INTRODUÇÃO}

Desde a infância, o campo escolar proporciona um papel importante na vida das crianças. Para além da aquisição de conhecimentos científicos, entretanto, o lócus abrange interações, experiências e conhecimentos cotidianos que, por sua vez, devem ser considerados no processo de aprendizagem. Quando se fala em Educação Infantil tal constatação torna-se ainda mais evidente, pois, como define a Base Nacional Comum Curricular (BRASIL, 2017), é necessário possibilitar os direitos de brincar, conviver, participar, explorar, expressar e conhecer-se.

Dentro desse contexto, o trabalho com sentimentos e emoções mostra-se relevante na aprendizagem escolar, pois possibilita um parâmetro que transpassa a mera aquisição de conhecimentos e insere-se na busca da própria identidade. Isso posto, o presente estudo é resultado de um estágio supervisionado na docência de Educação Infantil do curso de Pedagogia da Universidade Federal do Rio Grande do Norte/Centro de Ensino Superior do Seridó/Campus Caicó (UFRN/Ceres/Caicó), e possui o objetivo de analisar a temática "sentimentos e emoções" no contexto da Educação Infantil e sua influência nas relações interpessoais e no processo de ensino-aprendizagem.

Do mesmo modo, cabe salientar a pertinência das razões pelas quais se justificam o desenvolvimento e a elaboração do presente trabalho, dentre as quais destaca-se a busca por contribuições para a produção de conhecimentos nesta área, somado à pretensão de aproximação entre a universidade e as instituições públicas escolares. Compreende-se, portanto, que o estudo, proveniente da experiência de estágio na Educação Infantil, auxiliou na construção de conhecimentos profissionais e pessoais referentes à educação.

A experiência conduz às possibilidades de vivenciar a dialética entre os saberes teóricos e a prática, de modo a prever sua indissociabilidade e sua inerência para esclarecer dúvidas, inconsistências, equívocos e, acima de tudo, inseguranças. Ao considerar que a criança não é uma "tábula rasa", é essencial, conforme explica Duarte (2003), que o professor instigue o conhecimento social originado a partir das interações. Além de relacionar-se com a sua realidade, a criança precisa, então, aprender a se autoconhecer, para que, assim, possa internalizar as habilidades necessárias à sua formação.

Cotidianamente, diferentes pesquisas revelam indivíduos em idade escolar que sofrem de ansiedade, transtornos e até mesmo depressão. Em vista disso, mesmo sabendo que tais questões devem ser tratadas clinicamente por profissionais especializados, torna-se possível questionar: Em que a escola contribui para reverter essa situação? O fato é que, por vezes, tais quesitos são negligenciados pelos próprios profissionais, seja por naturalizar dadas questões ou mesmo pela concepção de que os objetos de conhecimentos são mais relevantes.

Os educadores não precisam desmistificar a educação fornecida na escola. Desse modo, interpõe-se que, congruente com os conteúdos necessários à formação, seja possível inserir o trabalho com sentimentos e emoções, pois tal quesito fortalece a personalidade e inclui a importância consciente da realização de suas atividades.

No que diz respeito à estrutura do presente trabalho, pode-se afirmar que está disposto da seguinte forma: 
- Em um primeiro momento trata acerca dos sentimentos e emoções na aprendizagem escolar. Para tanto, recorre-se aos contributos teóricos de autores como Vigotsky (2002), Piaget (1954), Bettelheim (1980), Freire (1996), entre outros. Além disso, expõe-se a importância de certas atividades para o trabaIho no campo escolar.

- Por conseguinte, salienta-se que, metodologicamente, o trabalho se classifica como qualitativo, a partir da revisão bibliográfica e da observação em uma escola do município de Caicó no Rio Grande do Norte, a qual atende crianças nas etapas da Educação Infantil e Ensino Fundamental - Anos Iniciais.

O estudo partiu, a priori, de um período de observações com registro em diário de campo, seguido de intervenções realizadas ao longo de cinco dias ininterruptos. A pesquisa foi desenvolvida com alunos do nível IV da Educação Infantil que, juntos, totalizam 17 crianças. Logo, a partir das observações foi possível constatar e delimitar as questões a serem trabalhadas e, por meio de ações que englobam a construção de um projeto de atuação pedagógica, estabeleceu-se uma práxis que foi ao encontro das necessidades encontradas na turma que, por sua vez, resultou na dificuldade de compreensão e entendimento dos sentimentos e emoções no campo do eu, do outro e do nós.

Além disso, torna-se possível ponderar acerca das atividades realizadas ao longo do estágio e de sua influência nas relações interpessoais das crianças. Diante disso, além das atividades propostas no primeiro momento, são evidenciadas outras tarefas que fizeram parte da pesquisa realizada e que serviram como suporte para o processo de aprendizagem escolar.

\section{OS SENTIMENTOS E EMOÇÕES NA EDUCAÇÃO ESCOLAR}

A princípio vale efetuar distinção entre os sentimentos e emoções, pois, como bem afirmam Casanova, Sequeira e Matos e Silva (2009), as emoções são públicas e inconscientes, originadas a partir de um impulso neural, existindo as primárias, que são fisiológicas, e as secundárias, que são provenientes do comportamento humano. Já quanto aos sentimentos, os autores inferem que estes se constituem conscientemente, considerando que a emoção se torna filtrada nos centros cognitivos do cérebro.

Nesse contexto, o trabalho com sentimentos e emoções na sala de aula pode parecer uma tarefa complexa, uma vez que habitualmente se dissemina um discurso de que "Com o tempo, eles aprendem". Ao ponderar essa constatação, negligencia-se a possibilidade de a criança identificar e reconhecer seus sentimentos e emoções, sobretudo na Educação Infantil, e, como pode-se constatar na Base Nacional Comum Curricular (BNCC), é necessário

Utilizar diferentes linguagens - verbal (oral ou visual-motora, como Libras e escrita), corporal, visual, sonora e digital -, bem como conhecimentos das linguagens artística, matemática e científica, para se expressar e partilhar informações, experiências, ideias e sentimentos em diferentes contextos e produzir sentidos que levem ao entendimento mútuo (BRASIL, 2017, p. 9).

Piaget (1959) enfatiza que o equilíbrio dos sentimentos e das relações sociais acontece a partir de uma estabilização gradual da idade. Desse modo, para que isso aconteça é necessário inserir as crianças em situações que as possibilitem expressar 
seus anseios. Ao levar-se em consideração que a base familiar nem sempre fornece subsídios suficientes para que isso aconteça, é no lócus escolar que muitas dessas relações serão estabelecidas, precisando, assim, ser incluídas no processo de aprendizagem.

O autor ainda traz uma visão que procura entender a criança sob uma vertente biológica do seu desenvolvimento. Desse modo, afirma que o indivíduo perpassa por estágios de desenvolvimento, tais como sensório-motor, pré-operacional, operacional concreto, operacional formal. Por mais, contudo, que em algumas dessas fases a criança possa apresentar comportamentos que sejam considerados "naturais" ao seu estágio de desenvolvimento, isso não valida o fato de o professor negligenciar o trabalho com essas questões.

Encaminhar-se-á no sentido de um comportamento marcado por uma experiência fluida, em mudança e plenamente receptiva dos seus sentimentos pessoais diferenciados. Na consequência deste "movimento" é que se dá uma evolução da personalidade, das emoções e do comportamento no sentido da saúde e da evolução psíquica, assim como das relações mais realísticas com o "eu", os outros e mundo circudante (CASANOVA; SEQUEIRA; MATOS E SILVA, 2009, p. 20-22).

Do mesmo modo, seria a relevância das decisões político-administrativas das escolas, mais especificamente de Educação Infantil, ao convergir com o Estatuto da Criança e do Adolescente (2002), o qual define que é dever do Estado assegurar os direitos à Educação Infantil para crianças de zero a cinco anos de idade, além de ser condizente com as Diretrizes Curriculares Nacionais da Educação Infantil (BRASIL, 2009), documento político, social e pedagógico que visa a garantir uma educação de qualidade e que fornece as orientações gerais para os sistemas de ensino.

As Diretrizes Curriculares Nacionais para a Educação Infantil articulam-se com as Diretrizes Curriculares Nacionais da Educação Básica e reúnem princípios, fundamentos e procedimentos definidos pela Câmara de Educação Básica do Conselho Nacional de Educação, para orientar as políticas públicas na área e a elaboração, planejamento, execução e avaliação de propostas pedagógicas e curriculares (BRASIL, 2009, p. 18).

Destaca-se a importância das boas relações interpessoais em contramão aos casos de bullying e preconceito que podem vir a comprometer o aluno em seu ambiente escolar, pois, como afirma Freire (1996, p. 103), "o clima de respeito que nasce de relações justas, sérias, humildes, generosas, em que a autoridade docente e as liberdades dos alunos se assumem eticamente, autentica o caráter formador do espaço pedagógico". Comunicar-se com o aluno e gerar um ambiente seguro e harmonioso, portanto, acaba por cooperar para o cotidiano do professor bem como para o do seu aluno.

Pormenores assim da cotidianeidade do professor, portanto igualmente do aluno, a que quase sempre pouca ou nenhuma atenção se dá, têm na verdade um peso significativo na avaliação da experiência docente. O que importa, na formação docente, não é a repetição mecânica do gesto, este ou aquele, mas a compreensão do valor dos sentimentos, das emoções, do desejo, da insegurança a ser superada pela segurança, do medo que, ao ser "educado", vai gerando a coragem (FREIRE, 1996, p. 20).

Nesse contexto, é importante que a gestão tenha como meta instrumentalizar formas que permitam que a criança consiga garantir seu processo de ensino-aprendizagem e que expresse seus sentimentos por meio de diferentes formas. Para tanto, faz-se necessário adentrar-se no currículo. 
O currículo é a concretização, a viabilização das intenções e orientações expressas no projeto pedagógico [...] no geral, compreende-se o currículo como um modo de seleção da cultura produzida pela sociedade, para a formação dos alunos; é tudo o que se espera que seja aprendido e ensinado na escola (LIBÂNEO; OLIVEIRA; TOSCHI, 2013, p. 489).

A partir disso é possível indagar-se: Como trabalhar os sentimentos e emoções no campo escolar? Para responder a essa questão é necessário salientar que existem diferentes formas de inserir essa temática na escola. Tendo como referência a Educação Infantil, todavia, torna-se possível apresentar duas delas, que são: a contação de história e a brincadeira.

Bettelheim (1980) afirma que a criança está sujeita a sentimentos de solidão e isolamento, e, além disso, constantemente precisa lidar com seus conflitos internos. Diante disso, o autor salienta que ao ler ou ouvir contos de fadas a criança consegue relacionar situações imaginárias com as da realidade que ela vivencia, possibilitando um conforto para certas situações de abandono e violência, entre outras.

Mas a suprema importância dos contos de fadas para o indivíduo em crescimento reside em algo mais do que ensinamentos sobre as formas corretas de se comportar neste mundo - tal sabedoria é plenamente suprida na religião, mitos e fábulas. As estórias de fadas não pretendem descrever o mundo tal como é, nem aconselham o que alguém deve fazer. Se o fizessem, o paciente hindu seria induzido a seguir um padrão imposto de comportamento - o que não só é péssima terapia, como também o oposto de terapia. $O$ conto de fadas é terapêutico porque 0 paciente encontra sua própria solução através da contemplação do que a estória parece implicar acerca de seus conflitos internos neste momento da vida [...] (BETTELHEIM, 1980, p. 24).

Além dos contos de fadas existem outras possibilidades de contação de histórias. Uma delas configura-se pela ficção. Diante disso, ao ser inserida nas práticas culturais possibilita refinar a Teoria da Mente $^{4}$ no que diz respeito à sensibilidade interpessoal. 0 indivíduo envolve-se na construção de personagens com situações bastante parecidas com as que ele vivencia, mas que, no entanto, não são suas situações reais (KIDD; CASTANO, 2013).

Na ficção literária o leitor precisa preencher lacunas e significados que não estão detalhados de forma explícita. Além disso, as ações, na maioria dos casos, rompem com as expectativas do leitor, fazendo-os se basear em processos da Teoria da Mente para inferir algo que poderá acontecer, identificando e reconhecendo reações que são utilizadas e que representam umas das utilidades da Teoria (KIDD; CASTANO, 2013).

Lidando com problemas humanos universais, particularmente os que preocupam o pensamento da criança, estas estórias falam ao ego em germinação e encorajam seu desenvolvimento, enquanto ao mesmo tempo aliviam pressões pré-conscientes e inconscientes. À medida em que as estórias se desenrolam, dão validade e corpo às pressões do id, mostrando caminhos para satisfazê-las, que estão de acordo com as requisições do ego e do superego (BETTELHEIM, 1980, p. 6).

A Teoria da Mente constitui-se em atribuir sentimentos e intenções aos comportamentos das pessoas. Assim, pode-se afirmar que isso ocorre a partir das interações que são estabelecidas. 
Já no que concerne às brincadeiras, como forma de promover o reconhecimento dos sentimentos e emoções no contexto educacional, pode-se afirmar que Zoia Prestes, em entrevista realizada por Vasconcelos, Simão e Fernandes (2014), salienta que, para Vigotsky, a brincadeira atua no desenvolvimento da imaginação, sendo, portanto, uma atividade guia na infância. Por conseguinte, a partir de brincadeiras, é possível que o estudante identifique e reconheça diferentes emoções e sentimentos.

[...] Uma atividade que a criança precisa ter liberdade para exercer. Estou falando de tempo, espaço e convivência que é uma atividade que traz elementos importantes de observação para um educador. Isso é importante para o desenvolvimento da fala. A criança vai brincar o tempo inteiro? Obviamente que não! Não estou falando disso, mas é preciso organizar o tempo e o espaço para que ela possa brincar. Para que a criança tenha estas possibilidades [...] (VASCONCELOS; SIMÃO; FERNANDES, 2014, p. 350).

Em vista dos fatos mencionados torna-se essencial destacar que o trabalho com sentimentos e emoções no contexto escolar é de suma importância para a aprendizagem da criança, uma vez que considera a subjetividade. Além disso, ao não considerar tais educandos enquanto "tábulas rasas", que chegam à escola desprovidos de quaisquer problemas, faz-se necessário que tal trabalho comece na Educação Infantil e se dissemine pelo resto do processo educacional.

\section{METODOLOGIA}

O estudo parte de uma metodologia caracterizada pela pesquisa exploratória (TRIVINÕS, 1987), a qual permite ao pesquisador expandir seu conhecimento a respeito de um determinado problema, de modo que esse tipo de investigação não exime a revisão bibliográfica, entrevistas, observações, etc. É oportuno destacar o seu caráter qualitativo, compreendendo um enfoque mais subjetivo, à medida que também promove a coleta e análise de dados.

Em conformidade, é essencial a revisão bibliográfica com autores e teóricos que trazem abordagens pertinentes para as discussões realizadas, como Freire (1996), que vem subsidiar a fala sobre educação, trazendo suas contribuições por meio de uma educação emancipadora. Ademais, autores, como Bettelheim (1980), discutem, por meio de um prisma psicanalítico, a contação de história e sua relevância no entendimento do eu. Somam-se, ainda, Vigotsky (2002) e Piaget (1954) e seus pensamentos, que se direcionam consideravelmente à criança, entre outros autores que possuem papel essencial no estabelecimento de uma concreta fundamentação teórica.

A pesquisa bibliográfica é desenvolvida a partir de material já elaborado, constituído principalmente de livros e artigos científicos. Embora em quase todos os estudos seja exigido algum tipo de trabalho desta natureza, há pesquisas desenvolvidas exclusivamente a partir de fontes bibliográficas. Parte dos estudos exploratórios podem ser definidos como pesquisas bibliográficas, assim como certo número de pesquisas desenvolvidas a partir da técnica de análise de conteúdo (GIL, 1999, p. 44).

A partir disso concretiza-se uma pesquisa que explora e aciona mecanismos que possibilitam o trabalho com alunos da rede pública de ensino e que, de maneira recíproca, permite uma troca entre escola-universidade trazendo contribuições no campo do conhe- 
cimento. Ademais, aumenta-se o acervo de produções na área da educação, à proporção que abre caminhos para estudos e aprofundamento da pesquisa aqui lançada, recomendada, principalmente, para professores, graduandos e demais interessados na temática.

\section{O CAMINHO QUE LEVA À EMPATIA E À COMPREENSÃO DO PRÓPRIO EU}

Ao se deparar com o comportamento dos alunos ante as relações estabelecidas dentro de sala de aula, tanto entre professor e aluno como entre os próprios alunos, é imprescindível destacar que a justificativa de se trabalhar com a temática "Sentimentos e emoções" se deu, primeiramente, em meio às observações realizadas, cuja constatação das intrigas e exclusões dentro do ambiente escolar encaminharam as pesquisadoras para a construção de um projeto nessa perspectiva (Figura 1).

Figura 1 - Projeto de atuação pedagógica

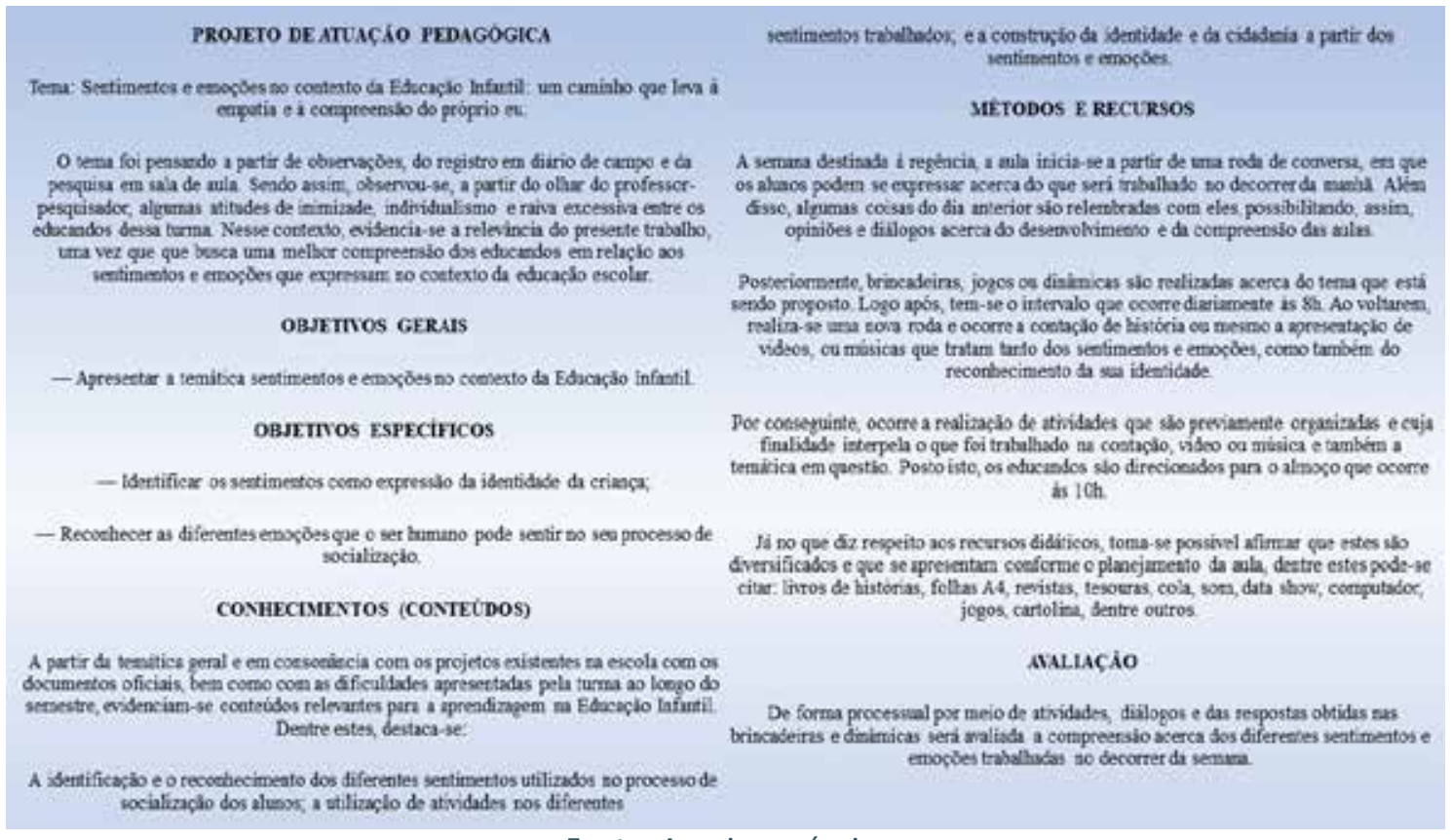

Fonte: Arquivo próprio.

O projeto de atuação pedagógica auxiliou na condução de toda a intervenção. Nele destacou-se as pretensões a respeito da temática, à medida que firmou objetivos a serem atingidos por meio de conteúdos e métodos que se foram desdobrando em ações realizadas por todo o período estabelecido, no qual, processualmente, foram avaliados e, ainda mais, materializados em formas de produções do público discente.

Lembramos que realizar planos e planejamentos educacionais e escolares significa exercer uma atividade engajada, intencional, científica, de caráter político e ideológico e isento de neutralidade. Planejar, em sentido amplo, é um processo que visa dar respostas a um problema, através do estabelecimento de fins e meios que apontem para a sua superação, para atingir objetivos antes previstos, pensando e prevendo necessariamente o futuro, mas sem desconsiderar as condições do presente e as experiências do passado, levando-se em conta os contextos e os pressupostos filosófico, cultural, econômico e político de quem planeja e de com quem se planeja (PADILHA, 2001, p. 63). 
Nesse âmbito, um dos episódios presenciados foi que algumas alunas não se sentavam ao lado de outras pelo fato de uma terceira aluna não querer, e isso acabou por gerar intrigas que se prolongaram durante todo o período de observação, deixando transparecer a dificuldade de lidar com os diferentes sentimentos que costumam ser despertos nas relações sociais, dentre eles o ciúme, a inveja, a raiva e o egoísmo. Nesse contexto, a série de intrigas resultou na solidão de uma das alunas. Essa situação ficou tão perceptível que o pai da vítima notou e comentou com a professora. Apesar das inúmeras tentativas da professora em integrar e tornar a relação entre as meninas da sala mais harmoniosa, a situação continuou.

Ainda no que diz respeito às relações interpessoais, de outro lado encontram-se os meninos e a prevalência da violência e dos picos de raiva por parte, mais especificamente, de um dos alunos, que, por sua vez, atinge todo o grupo de meninos com provocações e situações violentas. A todo instante a professora chama a atenção deste aluno, que acaba não participando das atividades e discussões em sala de aula, decorrente da falta de atenção por estar o tempo todo disperso pelo ambiente.

Em meio às relações interpessoais é possível mensurar o quanto o trabalho coletivo ajuda na harmonia e na construção do espírito empático na sala de aula, pois alunos nutridos de boas intenções e preparo emocional abrem espaço para que isso aconteça. A escola, como lócus de intensas relações entre os sujeitos, tende a gerar conflitos diários, porém trabalhar os elementos que circundam é primordial.

O entendimento da dinâmica de construção do indivíduo e da dinâmica de construção do social mostra que eles são interdependentes, não só no sentido de que um depende do outro, mas sim no sentido em que o individual e o social são interconstituintes. O indivíduo é indivíduo na medida em que é social, e o social, por sua vez, surge à medida que seus componentes são indivíduos (FARIAS, 2007, p. 26).

Após a etapa de observações partiu-se para as intervenções, que visaram a trabaIhar os sentimentos e as emoções. Estes, nesta fase escolar, possuem uma configuração complexa e sensível, o que compromete o entendimento dos alunos sobre seu próprio eu, como também sobre o que se passa com seus pares. Assim, a execução do projeto ocorreu a partir de um planejamento prévio. Mesmo, conquanto, que o planejamento tenha sido organizado com antecedência, isso não o tornou fixo e imutável; pelo contrário, sempre que necessárias novas alterações e pesquisas eram realizadas. Dessa maneira, é importante que a pesquisa faça parte do processo de formação dos docentes e que seja compreendida como um elemento indispensável na sua formação.

A pesquisa e a reflexão são atos de retomada, reconsiderando os dados disponíveis, revisando, vasculhando numa busca constante de significado. Assim, pesquisar é examinar detidamente, prestar atenção, analisar com cuidado. É uma espécie de entrega interpretativa que teoriza a prática e pratica a teorização como possibilidade de compreensão e superação dos limites de nosso ser que se lança no horizonte do sentido da compreensão. Isso tudo está radicalmente ligado à forma como também nos constituímos e construímos no que somos ao sermos atingidos pelo conhecimento [...] (GHEDIN; OLIVEIRA; ALMEIDA, 2015, p. 58). 
Do mesmo modo é que, a fim de atender aos objetivos e à temática central do referido projeto, bem como às problematizações observadas, torna-se essencial destacar as atividades que foram realizadas em sala de aula ao longo de cinco dias. Assim, o primeiro dia de intervenção começou a partir de uma roda de conversa, na qual os alunos tinham a oportunidade de dialogar acerca do que eles acreditavam que aconteceria no decorrer da manhã. Em conformidade a isso, definia-se o tema a ser trabalhado à medida que, no mesmo momento, também se procurava adaptação ao que os educandos discorriam, pois, como afirma Alarcão (2005), é extremamente importante saber adaptar-se à sua autoformação e estratégias de como desenvolver um trabalho de sucesso em meio ao espaço escolar.

Por conseguinte, foi realizada uma dinâmica que tratava a respeito dos sentimentos, com a utilização de algumas palavras e de uma roleta que continha números que indicavam diferentes sentimentos. Os estudantes iam sendo sorteados para expressá-los, na medida em que os demais reconheciam qual estava sendo encenado.

Nesse contexto, vale salientar a importância de se trabalhar com tais questões, pois, quando a criança sabe reconhecer tais emoções, expressões, reações e representações físicas e sonoras, possibilita-se um desenvolvimento da sua psique. Essa turma, no entanto, e, mais precisamente, nesse primeiro dia de intervenção, demonstrou não reconhecer quase nenhuma expressão dos sentimentos apresentados, de forma que esse quesito influenciava, sobretudo, nas relações interpessoais da sala de aula.

Posteriormente foi realizada a contação de uma história com a utilização de fantoches, intitulada "Tenho monstros na barriga". Sendo assim, discutia-se de forma lúdica como os sentimentos e emoções poderiam fazer parte da nossa vida e como eles influenciavam as situações diárias da nossa existência. Logo após houve uma discussão sobre o que a história tratava e uma atividade foi realizada com o objetivo de identificar, por meio de um desenho, algum sentimento apresentado na história que eles já haviam sentido. No momento posterior ao almoço foi realizada a roda de conversa final, e cada aluno teve a possibilidade de apresentar o seu desenho para os colegas e nomear o sentimento que ele representava.

No segundo dia de intervenção foi feita uma dinâmica com a utilização de um barbante, na qual as crianças, para entrarem no círculo, deveriam dizer uma mensagem positiva para seu colega. Dessa forma, tal atividade foi pensada por causa das circunstâncias encontradas no período de observação/coparticipação, na qual se presenciou momentos de inimizades e violências físicas. Posto isso, a dinâmica trabalharia a necessidade de se cultivar os bons sentimentos.

Em sequência houve uma contação de história intitulada "O peixinho arco-íris", na qual se trabalhava a diversidade e a identidade presente em cada criança. A partir disso relacionou-se com os sentimentos e emoções, haja vista que, de forma dialogada, se afirmava que, como todos são diferentes, é essencial saber respeitar os sentimentos do outro e, principalmente, cultivar princípios bons. Por conseguinte, pode-se destacar a importância da contação de história para as crianças, pois, como afirma Bettelheim (1980), é na estória que a criança vai encontrando alguns significados da sua vida, e uma estória que realmente prenda a atenção da criança é aquela que traz elementos da sua personalidade. 
Posteriormente, houve a confecção de um cartaz com moldes de peixes recortados e colados pelos próprios alunos, que traziam, em sua essência, atitudes ou sentimentos que favorecessem uma amizade harmoniosa. Buscou-se, assim, atender tanto às temáticas centrais dos sentimentos e reconhecimento de letras como também à coordenação motora fina, que foi mais um aspecto identificado pela docente no período de observação.

Ao final desse dia ainda foi realizada a exposição do cartaz, e cada criança teve a oportunidade de apresentar seu peixinho e justificar o porquê da escolha de determinada atitude ou o sentimento para a formação de uma amizade coletiva.

O terceiro dia, destinado para a regência em sala de aula, teve início com uma roda de conversa que incidia em aspectos referentes aos dois dias anteriores e reafirmava o que seria trabalhado naquela manhã. Posteriormente foi realizada uma brincadeira popularmente conhecida como o mestre mandou. Nesse momento os educandos foram classificados por números aleatórios, e, para a realização das tarefas, eles precisavam reunir-se com os colegas que estivessem com o mesmo número, independentemente de ser do mesmo gênero ou não. Posto isso, pode-se afirmar que tal brincadeira possibilitou o trabalho com noções numéricas, relações interpessoais e também o faz de conta, quando a criança é levada a imaginar diferentes situações.

Em sintonia com a brincadeira realizada vale salientar que Prestes (VASCONCELOS; SIMÃO; FERNANDES, 2014), estudiosa de Vigotsky, afirma que nos trabalhos desenvolvidos pelo teórico ele destaca a brincadeira como um papel fundamental na "neo" formação da criança, principalmente brincadeiras que trazem atrelado o faz de conta, considerando que possibilita o desenvolvimento da imaginação, sendo, portanto, uma atividade-guia da infância.

Em seguida houve a contação de história "Nunca conte com ratinhos," a qual trabalhava desde a noção de números até o diálogo, a argumentação e a justificativa de algumas situações parecidas com as da realidade que muitas crianças enfrentam. Por conseguinte, os alunos realizaram uma atividade que tinha por princípio a escrita de alguns sentimentos e a contagem de letras e palavras. Por fim, realizou-se a confecção de uma dobradura de uma figura de rato, estabelecendo-se conexões com a história contada.

Já no quarto dia executou-se uma dinâmica na qual os educandos tinham de reconhecer seus sentimentos a partir de situações cotidianas. Esse momento foi extremamente gratificante do ponto de vista profissional, pois, no primeiro dia de intervenção realizada, os alunos demonstraram não reconhecer os sentimentos e emoções evidenciados; já nesse quarto dia, todos que participaram da dinâmica conseguiram relacionar o sentimento expresso com a situação planejada.

Logo após os educandos puderam ouvir uma música chamada emoções, a qual relacionava-se com o tema central e também com situações da sua cultura, haja vista que, como bem enfatiza Vigotsky (2002), a estruturação do pensamento do indivíduo e as habilidades cognitivas não são resultados de fatores congênitos, mas, sim, dos hábitos sociais e atividades da cultura em que o indivíduo se envolve. Por isso, a importância de trazer elementos da cultura e do convívio social que a criança faz parte. 
Finalmente foi realizada uma atividade na qual os alunos puderam reconhecer os sentimentos que eles mais utilizavam e também desenvolver habilidades de coordenação motora fina, uma vez que essa havia sido mais uma questão observada como necessária de também ser trabalhada nos dias de observação.

No último dia destinado à regência a aula iniciou-se a partir de uma roda de conversa inicial, na qual os alunos tiveram a oportunidade de relembrar o que havia sido realizado no dia anterior. Por conseguinte, deu-se início a uma brincadeira na qual algumas letras referentes aos sentimentos trabalhados foram espalhadas pela sala, tendo como objetivo que as crianças encontrassem as letras e justificassem o que o sentimento formado nas palavras significava para elas. Assim, tal dinâmica foi pensada a partir do que afirma Soares (2006), quando salienta que a alfabetização e o letramento são processos distintos, mas também indissociáveis. Por isso, mesmo que a Educação Infantil não tenha a finalidade de alfabetizar a criança, torna-se imprescindível inclui-la em contexto de palavras, letras, identidade cultural, dentre outros.

Também foi realizada a contação de história "A menina e seus pontinhos", que abordava diferentes sentimentos e emoções trabalhados no decorrer da semana a partir de situações cotidianas próprias da realidade infantil.

Logo, em seguida, as crianças realizaram uma atividade que consistia em desenhar o seu boneco dos pontinhos e escrever os sentimentos que eles gostariam que o seu desenho tivesse. Além disso, os educandos também tiveram a oportunidade de expor os seus desenhos e explicar, de forma interativa, o que haviam expressado. Finalmente, a fim de estabelecer um maior vínculo de amizade e solidariedade dentro da turma, foi executado um jogo intitulado Amigo do Coração, no qual cada criança sorteava um colega e tinha de presenteá-lo com um cartão.

Ao longo desse percurso foram inúmeras as atividades promovidas pelas estagiárias, como mostra a Figura 2.

Figura 2 - Atividades realizadas pelos alunos

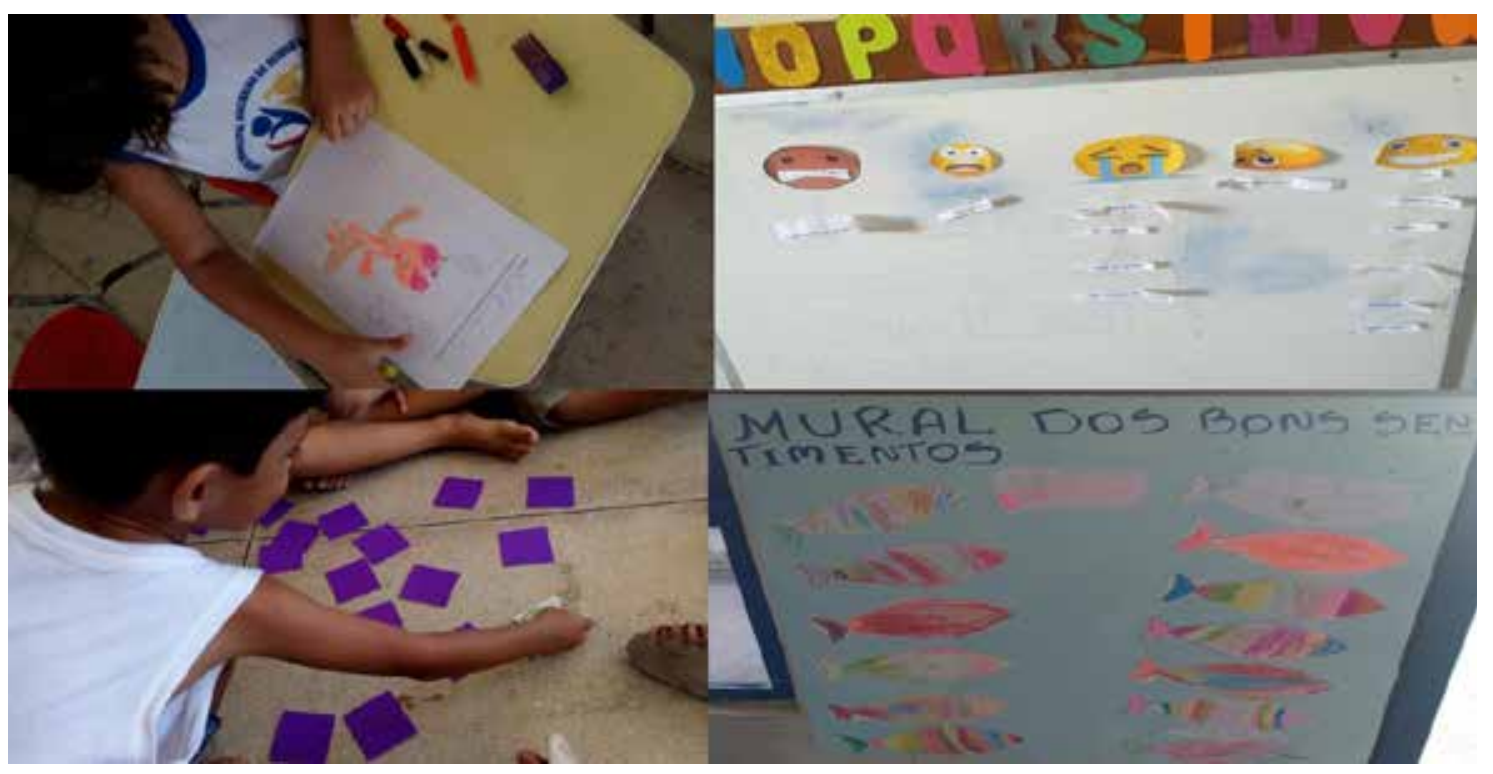

Fonte: Arquivo próprio. 
Todas as atividades, portanto, conduziam os alunos para a interpretação, compreensão dos sentimentos e emoções dentro da perspectiva da empatia, haja vista que os conflitos existentes eram envolvidos por cargas emocionais que acentuavam as tensões dentro de sala de aula.

\section{CONSIDERAÇÕES FINAIS}

Ao iniciar este trabalho partiu-se da necessidade de discorrer a respeito da temática "Sentimentos e emoções" no ambiente escolar e sua influência nesse meio, seja pelas relações estabelecidas diariamente ou pela capacidade que esse conjunto de fatores tem de refletir no processo de ensino-aprendizagem ou na dinâmica de sala de aula. Logo, a atuação do professor engajado em tais princípios se encaminha para o entendimento, convivência e controle desses sentimentos e das emoções por parte das crianças em situações cotidianas, a fim de promover o bem-estar e harmonia entre os sujeitos.

Para isso foi necessário trilhar um caminho que envolveu desde observações até intervenções. Estas deram-se por meio de um projeto que surtiu efeitos desejados, embora o tempo não tivesse sido ideal para a obtenção de resultados mais concretos que possibilitassem um trabalho de longo prazo. As participações e as produções ao final de cada dia de intervenção, entretanto, mostraram um entendimento maior a respeito da temática quando comparados, por exemplo, ao primeiro dia de intervenção e aos momentos observados.

No processo buscou-se a reafirmação teoria-prática, além da caminhada ao encontro da concretização dos objetivos propostos. Já no que diz respeito aos desafios encontrados, pode-se destacar a necessidade de um maior tempo de observação e, consequentemente, do período de regência, pois somente assim seria possível compreender, de forma mais profunda, o perfil da turma trabalhada e ainda promover uma ação de longo prazo.

A aprendizagem e as relações interpessoais tendem a ser mais efetivas quando trabalhados os sentimentos e emoções dentro de sala de aula, de modo que criam um ambiente de autoconhecimento por parte dos estudantes com relação a seu próprio eu, como também permitem entender o outro e todo o aparato emocional que ele pode carregar. Dessa forma, colocar-se no lugar do outro é primordial para a promoção de relações saudáveis, à medida que capacita para uma aprendizagem com mínimas intervenções negativas e conflitos.

A pesquisa caracteriza-se, portanto, como relevante, pois permite o aprofundamento teórico-prático a respeito de temáticas que permeiam a educação, progredindo, assim, na pesquisa e aumentando o acervo de produções acadêmicas, servindo como base para futuras pesquisas e estudos.

\section{REFERÊNCIAS}

ALARCÃO, Isabel. Formação reflexiva de professores: estratégias de supervisão. Porto Editora, 2005. BETTELHEIM, Bruno. A psicanálise dos contos de fadas. 3. ed. Rio de Janeiro: Paz e Terra, 1980. 366 p. BRASIL. BNCC - Base Nacional Curricular Comum. Brasília: SEE; MEC, 2017. 
BRASIL. Conselho Nacional de Educação. Resolução CNE/CEB no 5/2009. Diretrizes Curriculares Nacionais para a Educação Infantil. Brasília, DF: Diário Oficial da União, 18 jan. 2020.

BRASIL. Estatuto da criança e do adolescente: Lei Federal no 8069, de 13 de julho de 1990. Rio de Janeiro: Imprensa Oficial, 2002.

CASANOVA, Nuno; SEQUEIRA, Sara; MATOS E SILVA, Vítor. Alunos do 1o ano de Psicologia do Instituto Superior Manuel Teixeira Gomes (Portugal), 2009. Disponível em: https://www.psicologia.pt/artigos/textos/ TL0132.pdf

DE VASCONCELOS, Giselle Silva Machado; SIMÃO, Márcia Buss; FERNANDES, Sonia Cristina Lima. Entrevista com Dra. Zoia Prestes. Zero-a-Seis, v. 16, n. 30, p. 340-352, 2014.

DUARTE, Newton. Sociedade do conhecimento ou sociedade das ilusões. Campinas: Autores Associados, 2003.

FARIAS, C. H. B. As relações interpessoais na escola. Santa Maria: Universidade Federal de Santa Maria, 2007.

FREIRE, Paulo. Pedagogia da autonomia. São Paulo: Paz e Terra, 1996.

GIL, Antônio Carlos. Métodos e técnicas em pesquisa social. 5. ed. São Paulo: Atlas, 1999.

GHEDIN, Evandro; OLIVEIRA, Elisangela S. de; ALMEIDA, Whasgthon A. de. Estágio com pesquisa. São Paulo: Cortez, 2015.

KIDD, D. C.; CASTANO, E. Reading literary fiction improves theory of mind. Science, v. 342, n. 6.156, p. 377380. Published on-line, 3 Oct. 2013.

LIBÂNEO, José Carlos; OLIVEIRA, João Ferreira de; TOSCHI, Mirza Seabra. Educação escolar: políticas, estrutura e organização. 10. ed. São Paulo: Cortez, 2013. 542 p.

PADILHA, P. R. Planejamento dialógico: como construir o Projeto Político Pedagógico da escola. São Paulo: Editora Cortez, 2001.

PIAGET, Jean. A linguagem e o pensamento da criança. Trad. Manuel Campos. Rio de Janeiro: Fundo de Cultura, 1959. 307 p.

PIAGET, Jean. Inteligencia y afectividad. Tradução Maria Sol Dorin. Buenos Aires: Aique, 1954.

TRIVINÕS, Augusto Nibaldo Silva. Introdução à pesquisa em ciências sociais: a pesquisa qualitativa em educação. São Paulo: Atlas, 1987.

SOARES, Magna. Alfabetização e letramento: caminhos e descaminhos. 4. ed. São Paulo: Univesp, 2006. $5 \mathrm{p}$.

VIGOTSKY. Pensamento e linguagem. [S.I.]: Ridendo Castigat Mores, 2002. 